\title{
LUT
}

University

\section{Introduction: Innovation for Sustainability}

Bocken Nancy, Ritala Paavo, Albareda Laura, Verburg Robert

This is a Author's accepted manuscript (AAM) version of a publication

published by Palgrave Macmillan, Cham

in Innovation for Sustainability. Palgrave Studies in Sustainable Business In Association with Future Earth.

DOI: 10.1007/978-3-319-97385-2_1

Copyright of the original publication: (c) The Author(s) 2019

Please cite the publication as follows:

Bocken N., Ritala P., Albareda L., Verburg R. (2019) Introduction: Innovation for Sustainability. In: Bocken N., Ritala P., Albareda L., Verburg R. (eds) Innovation for Sustainability. Palgrave Studies in Sustainable Business In Association with Future Earth. Palgrave Macmillan, Cham

This is a parallel published version of an original publication. This version can differ from the original published article. 


\section{CHAPTER 1}

\section{INTRODUCTION: INNOVATION FOR SUSTAINABILITY}

\section{Chapter published in}

"Innovation for Sustainability: Business Transformations Towards a Better World"

Editors: Nancy Bocken, Paavo Ritala, Laura Albareda, Robert Verburg

Publisher: Palgrave, 2019

\section{Nancy Bocken}

Professor of Sustainable Business, Lund University IIIEE, Sweden

Visiting prof., Lappeenranta University of Technology, Finland

Associate prof., TU Delft.

\section{Paavo Ritala}

Professor of Strategy and Innovation

School of Business and Management

Lappeenranta University of Technology, Finland

\section{Laura Albareda}

Associate Professor of Sustainable Business

School of Business and Management

Lappeenranta University of Technology, Finland

\section{Robert Verburg}

Associate Professor in Management

Faculty of Technology Policy and Management

Delft University of Technology, The Netherlands

\section{Rationale and aims - why this book, why now?}

We are in a new geological epoch, the Antropocene by which the impacts that human development have caused on Earth systems put our resilience at risk (Steffen et al., 2011). Natural scientists have studied nine 'planetary boundaries' that determine Earth system resilience, and focus the attention on how human activities are transgreading them (Rocktröm, et al., 2009): climate change, rate of biodiversity loss, interference with the nitrogen and phosphorus cycles, stratospheric ozone depletion, ocean acidification, global fresh water use; land use change, chemical pollution and atmospheric aerosol loading. This analysis has also been integrated in global studies such as the IPCC 1.5C Special Report (2018) that shows how limiting global warming require challenging transitions in many dimension of human development, changing and transforming our energy, agricultural, industrial and urban systems fostering important innovation oriented towards sustainable development and climate action. 
We are deeply affected by Grand challenges such as climate change, economic and social inequality, as well as resource scarcity are increasingly recognized across the policy, business and academic domains (Ferraro et al., 2015). Such challenges have been formalized in 17 Sustainable Development Goals (SDG), such as climate action, clean water and sanitation, zero hunger, and reducing inequality adopted by the UN in 2015 calling for new collaborative solutions by governments, businesses, researchers and civil society organizations (George et al., 2016). These grand challenges are perhaps the biggest business opportunity of our times as suggested by Porter \& Kramer (2011). Resolving such challenges requires major innovation efforts, at the level of individual products and services, but also more broadly at the level of business models and social innovations, and major system-level transitions (Adams et al., 2016).

These themes are tremendously important, but certainly not new. In fact, there are many books and thousands of journal articles written at the intersection of business and sustainability (Bansal \& Song, 2017). There are also increasing numbers of contributions discussing sustainability-oriented innovation (e.g. Adams et al., 2016; Hansen et al., 2009) and sustainable business model innovation (e.g. Stubbs \& Cocklin, 2008; Boons \& LüdekeFreund, 2013). However, with this progress the field has grown exponentially leading to divergence in the views and the conceptualizations used.

To bridge this gap, our edited collection incorporates contributions in the intersection of innovation and sustainability fields of literature, representing a diversity of approaches in business, management and engineering. We also include cross-disciplinary approaches embedding for example, political research, system analysis and experimental research. In doing so, we aim to provide a comprehensive overview of the opportunities and challenges related to innovation for sustainability. Combining work from both emerging and established scholars, this book examines the topic from four scholarly perspectives: 1) Systemic approach / big picture 2) Strategy and leadership, 3) Measurement and assessment, 4) Tools, methods and technologies. These are preluded by short practitioner perspectives to introduce the four perspectives.

Furthermore, this book aims to be "solutions-driven", providing both academically sound but also practically applicable insights for fostering sustainable innovation. As a whole, the compilation of chapters provides a reflective as well as a critical understanding of the challenges that need to be solved. Thus, from a business perspective the book provides multiple insights on how to approach innovation for sustainability, but without one predefined 'recipe'. Rather it gives a critical insight on different aspects of Innovation for Sustainability.

Overall, this book aims to be a key resource for Master students, PhD students, and MBAs, but also scholars, practitioners and decision makers wanting to gain essential knowledge about the field of sustainable innovation. Key topics are the analysis of different approaches to sustainable innovation, sustainable business model innovation, circular economy, strategy and leadership, corporate responsibility, measurement and assessment mechanisms, impacts, tools and methods.

\section{Defining Innovation for Sustainability}

This book pursues to push forward the convergence in the disciplinary traditions of innovation management and sustainable business. While these fields have partly developed separately, we see the pursuit of positive environmental and social goals as innate to any innovation process. As such, this suggests that a separate field of Innovation for 
Sustainability would not be necessary in the future, as all innovation processes should include clear and traceable positive environmental, social and economic implications. This relates to what P. Drucker already wrote in 1954: 'Every single social and global issue of our day is a business opportunity in disguise.' With this progress in mind, in this book we are suggesting an integrative definition of Innovation for Sustainability (IfS), building on sustainability and innovation management fields. This definition is grounded both in our own thinking, as well as the variety of contributions in this book.

Innovation can be broadly described as a process of turning opportunity into new ideas and putting these into widely used practice (Tidd et al. 2005). It is vital for organizational survival, long-term growth, and organizational competitive advantage (Teece, 2010). Growing global resource, climate and humanitarian challenges have spurred organizations to embed social and environmental aspects as part of their economic value creation. Indeed, many companies nowadays see that long-term competitiveness can only be achieved this way (Hart \& Milstein, 2003; Porter \& Kramer, 2011). Thus, for an increasing number of firms, sustainability implies the creation, delivery and capturing of all three dimensions of value economic, social, and environmental - as part of their business model (see e.g. Boons et al., 2013; Iñigo et al., 2017).

Accordingly, we argue that companies should (and do) increasingly pursue Innovation for Sustainability - rather than innovation as a purely profit-oriented pursuit (Adams et al., 2016). Furthermore, IfS is seen as both a process and an outcome of pursuits that increase economical, ecological and social aspects of value creation. Such innovation is all but easy, but when successful, the rewards are high for both innovating actors as well as the societies they are embedded in (e.g. Porter and Kramer, 2011). In fact, IfS requires companies to foster complex transformation at both organizational and societal levels (e.g. Markard et al., 2012; Iñigo \& Albareda, 2016).

Innovation for Sustainability is an overarching umbrella concept that relates to the growing development of new products and services, processes, technologies, organizational practices, business models, and even whole 'systems' at networks such as cities (Fig. 1.1). (Adams et al., 2016). It can be regarded as a commercial introduction of products, services or productservice combinations, which, based on traceable assessment, has clear environmental and (or) social life cycle benefits over prior versions (Hansen and Grosse-Dunker,

2013). Organisations of all types and sizes are pursuing such innovations. However, it should be noted that sustainability-oriented system-based innovations are more innate to hybrid forms of businesses (e.g. benefit corporations and social enterprises) that are emerging where the profit motif is less dominant and social and environmental motives come to the foreground (Battilana and Dorado, 2010).

In existing businesses, IfS is an intentional change to an organizations philosophy and values and to its products, services, processes or practices to create social and environmental value as well as economic returns (Adams et al., 2016). In new and emerging businesses, it is often about the intentional design of such organisations with social and environmental value. It is apparent from separate innovation and investment literatures that often one dimension (e.g. environmental focus such as cleantech or a social focus) is more dominant (Bocken, 2015). As a result, in the more advanced and committed hybrid organizations, innovation for sustainability is growing as a complex adaptive system (Inigo \& Albareda, 2016) expanding innovation dynamics towards economic and social transformations. 
In summary, IfS may be classified by the innovation type (e.g. technology, process, product/ service, or business model), the dominant target (ecological and/ or social, coupled with economic) (Hansen et al., 2009) and level of disruption (incremental, radical) (Plieth et al., 2013). Typically, the assessment of impact will take a life cycle or value chain perspective (Hansen et al., 2009).

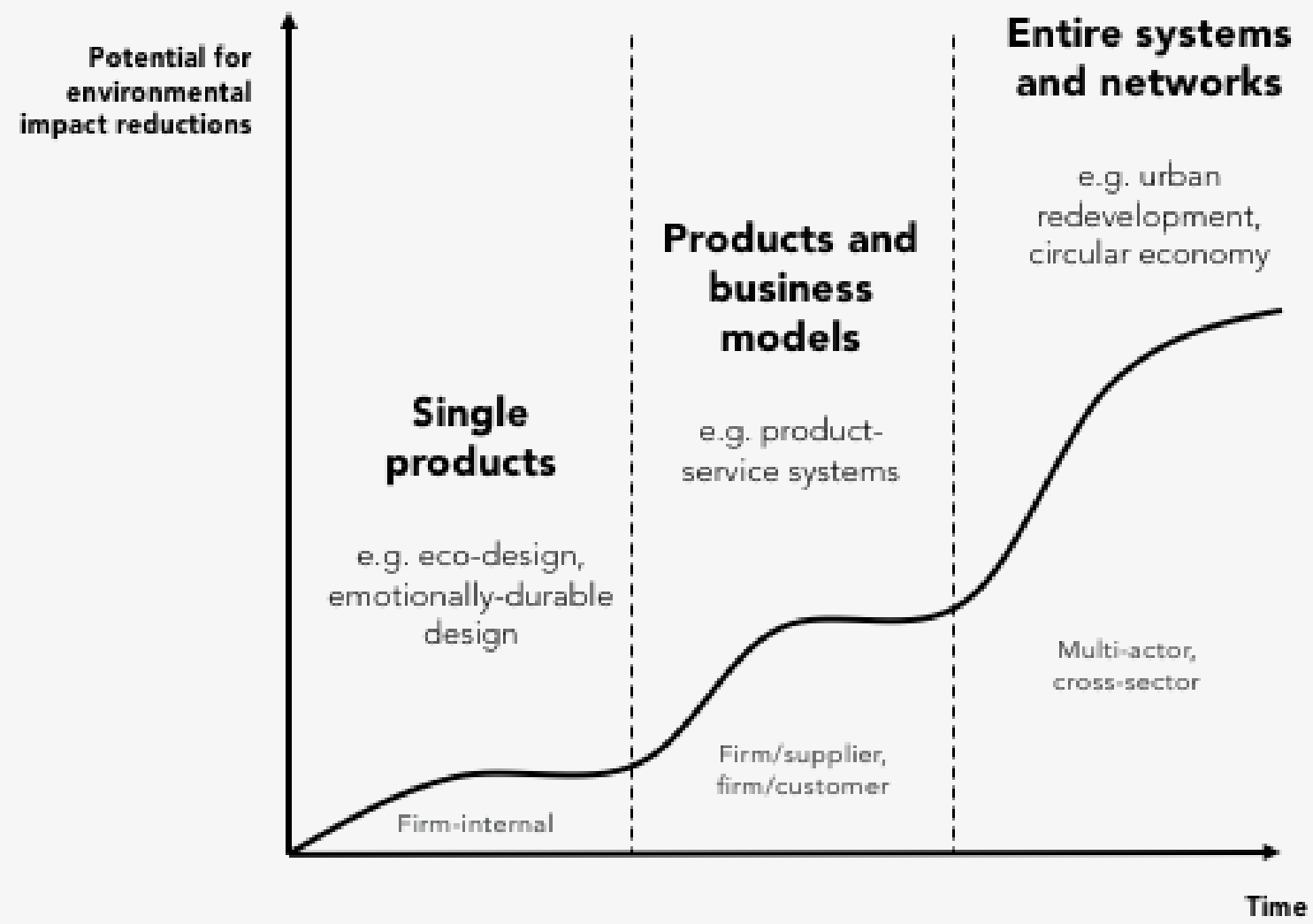

Figure 1.1 Innovation for Sustainability spectrum. (adapted from Konietzko et al. 2018; Adams et al., 2016 and Ceschin and Gaziulusoy 2016)

Based on the above discussion, we propose the following integrative definition for Innovation for Sustainability (IfS):

Innovation for Sustainability is about the intentional introduction of (radically) new or (incrementally) improved products and services or entire systems, which, based on traceable comparative analysis, lead to environmental and (or) social benefits over the prior version's physical life-cycle.

While this definition intends to be broad and inclusive, it is noteworthy to mention that the research field of innovation and sustainability is still nascent and the terminology has not converged. This is observable throughout the 23 chapters of this edited collection, where authors discuss concepts such as eco-innovation, sustainable innovation, sustainabilityoriented innovation, sustainable-business model innovation, and so on. This is certainly a reflection of cross-disciplinary nature of the author teams, as well as the field at large.

However, it might also provide to be of hindrance in the scholarly development of the field if authors use diverse concepts when referring to the same phenomena. As such, we believe that 
the converge in the terminology will gradually take place in the coming years, but at the moment the diversity of views might be beneficial in order to tease out all the necessary perspectives. Hopefully our book will help in its part in facilitating the conceptual development and cross-disciplinary understanding of innovation for sustainability.

\section{Structure and contents of the book}

'Innovation for Sustainability' - will incorporate four parts: 1) the big picture (systems approach), 2) strategy and leadership, 3) measurement and assessment, as well as 4) tools, and metrics for sustainable innovation. Figure 1.2 visually summarizes the four parts in the book, which are mutually complementary, and provide an overarching view to innovation for sustainability, as discussed in the following.

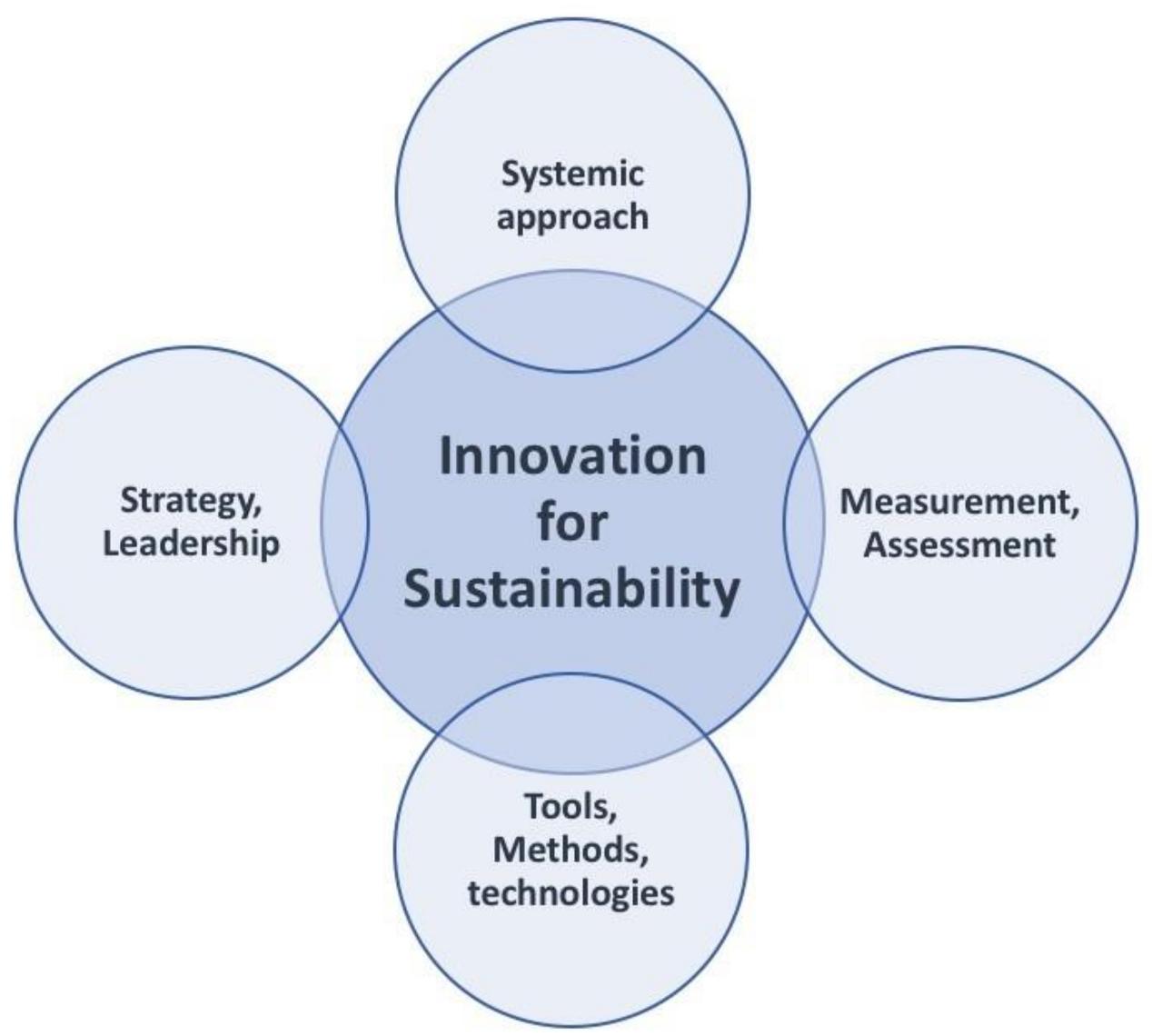

Figure 1.2. Overview of book structure

Part 1 on this book focuses on the big picture of the phenomenon of innovation for sustainability. Together these five chapters develop the managerial understanding of the topic, including a critical approach to IfS. The first two chapters summarize and reflect insights from the academic literature. While Chapter 2 proposes an interesting discussion about the three main ontologies adopted by researchers, Chapter 3 provides an in-depth bibliometric literature review that classifies their dissemination. Chapters 4 and 5 provide detailed evidence based on how companies engage in IfS and build different business approaches: environmental factors affecting businesses (Chapter 4), and different profiles of circular 
business model innovation (Chapter 5). Chapter 6 then explores the role of policy makers to support eco-innovation as key drivers to transition towards a green economy. In detail:

- Chapter 2 adopts a system view to innovation for sustainability and introduces three perspectives on the role of business as a driver for change in innovation and Sustainable Development. These include sceptical, pragmatic and idealistic perspectives, each involving a complex adaptive system analysis of the role of businesses. Based on these perspectives, the chapter provides a critical and reflective outlook to the challenges and opportunities of innovation for sustainability.

- Chapter 3 contributes to the big picture through a literature review and bibliometric analysis on innovation for sustainability. The impact and dissemination of this literature is classified five key discussions: strategic, operational, organizational, collaborative and systemic IfS. The bibliometric analysis shows how IfS literature has expanded from Business management, Strategy, Innovation and Operations to connecting to the main discussions in Environmental Sciences, Environmental Engineering and Ecology.

- Chapter 4 studies how environmental factors affect the engagement of businesses in innovation for sustainability. Looking at the literature on dynamic capabilities and sociotechnical transitions, the author draws on empirical evidence of eight cases of companies framing three different degrees of dynamism: reactive, challenging the environment and contributing to system building.

- Chapter 5 studies how companies in different settings engage in developing circular business model innovation. Based on case analysis in Denmark, the authors build a model for circular business based on three main approaches: internal, hybrid and systemic circular business model innovation.

- Chapter 6 investigates business-driven ecological innovation in green growth strategies. The authors explore the linkages between green growth and ecoinnovation. The main argument is that the growing fields of eco-innovation and sustainable business models are drivers towards the transition to a green economy, and must be adopted and supported in governmental policy strategies.

Part 2 of the book highlights the strategic and leadership aspects of Innovation for

Sustainability (IfS). The different chapters illustrate the nature and practice of innovationbased sustainable business strategies on the basis of state-of-the-art theory and the results of a number of original case studies. Illustrations range from retail businesses (Chapter 10), fashion companies (Chapter 11), horse-industry entrepreneurs (Chapter 12) to more established corporates (see Chapters 8 and 9). Given that the main building blocks of innovation are individuals' knowledge and ideas, the way employees are led and managed is a crucial factor in determining whether organizations are able to execute those innovation-based sustainable business strategies. Therefore, in this part, also leadership practiced for Ifs is highlighted in Chapters 7, 8 and 9.

- Chapter 7 explores the leadership challenges associated with sustainability by highlighting the current research evidence on the links between leadership and (sustainable) innovation.

- Chapter 8 provides an overview of the key leadership challenges in relation to sustainable innovation projects in large businesses. Examples from practice are provided and it shows that project managers are challenged by gathering the right information as well as to allocate resources wisely within sustainable innovation projects. 
- Chapter 9 provides the results of a case study on systemic innovation. This case shows that business leaders tend to hold back attempts at systemic innovation for sustainability due to structural impediments, uncertainty avoidance and conflicting aims within and between firms.

- Chapter 10 shows on example how business models in the retail sector can be innovated in order to ensure smarter and more sustainable business models on the basis of a normative framework. Central to this framework are: redesign, experimentation, service-logic, the circular economy, alliances, results and threedimensionality.

- Chapter 11 features localism as a strategy for business model innovation for sustainability. As a strategy, localism can generate various forms of shared value. The geographic proximity seems to enable reconnections between resources, people, place, community, and through environment that correlate with sustainability.

- In chapter 12 examples of strategies for enabling sustainable entrepreneurship are presented. This chapters shows that the choice for a specific sustainable entrepreneurship strategy highly depends on the valuation of environmental, economic, and social sustainability factors.

Part 3 of the book focuses on measurement and assessment of sustainable innovation. As a whole, the five chapters in this part provide a good overview of the state-of-the art in the field. The first two chapters (Chapters 13 and 14) provide insights of the broad-based challenges and opportunities in measuring and assessing innovation for sustainability. The remaining three chapters, on the other hand, provide more detailed evidence on the assessment and details of innovation processes for sustainable innovation. They include the interesting approach of "reversing materiality" (Chapter 15), design and systems thinking approach to sustainability impact (Chapter 16), as well as an examination of how strategic environmental goals affect product innovation (Chapter 17).

- Chapter 13 details the measurement challenges in innovation performance measurement in general, and combines those with the innovation for sustainability context. As a result, the chapter provides useful insights into how academics and practitioners can design different measurement schemes.

- Chapter 14 develops a series of propositions regarding the assessment of the impact of sustainable business models. Here, the authors outline particular principles that would ideally describe the breadth and detail of such assessment.

- Chapter 15 describes how companies can move from reactive materiality assessments to a more proactive approach. In particular, the authors suggest that firms can embed sustainable development goals (SDGs) in their strategic activities, effectively "reversing materiality".

- Chapter 16 draws from design sciences and systems thinking in describing how companies can better scale their sustainability impact. The chapter goes through principles that could help companies to be more adaptive and design-driven, and provides several illustrative examples from practice in this regard.

- Chapter 17 presents a mixed methods approach on explaining how companies' strategic environmental goals affect product innovation. The authors find quantitative evidence that pursuing environmental goals can be successfully be aligned with product innovation, and they illustrate these with qualitative insights.

\section{Part 4 describes Tools, Methods and Technologies that support Innovation for}

Sustainability. It includes novel perspectives on tools and methods for IfS and explores the 
role of new technologies and developments. The first two chapters (Chapter 18 and 19) discuss the topic of experimentation for sustainability and the circular economy and provide company cases as examples. Chapters 19 and 21 contribute to the broader discussion on Circular Economy. Chapter 20 is about games and gamification and their role in sustainable innovation. Chapters 22 and 23 reflect on role of digital technologies and platforms and their impacts on sustainability.

- Chapter 18 discusses the topic of Experimentation for Sustainability. It contrasts 'business experimentation for sustainability' to drive IfS with experimentation in the natural sciences. It provides insights on how the corporation Procter \& Gamble experiments during the sustainable innovation process.

- Chapter 19 describes a process-oriented approach to experimenting with circular business models including five broad stages. The case of the tools renting service pilot called Liiteri is introduced, which highlights various challenges and opportunities identified across the different process steps.

- Chapter 20 describe game-based approaches to sustainable innovation and how two game-based approaches - serious games and gamification - have been applied to sustainable innovation. Through various examples, the chapter explores potential merits and drawbacks to game-based approaches.

- Chapter 21 talks about the potential role of the Circular Economy as a particular "imaginary" and approach to drive institutional changes for sustainable innovation. The case of Sitra, the Finnish Innovation Fund, is described. It was found that the Circular Economy lens has a potential to create collective meaning towards innovation which fits the Finnish culture.

- Chapters 22 focuses on the role of digital technologies in innovation for sustainability. It explores the linkages between specific digital technologies and their economic, social and environmental impacts, as well as potential positive and negative implications.

- Chapter 23 discusses the potential role of online platforms in the Circular Economy. It develops a framework about the role of online platforms in the Circular Economy including online platforms as enablers of Circular economy markets; ways to operate product service systems; and places to co-create novel products and services.

\section{The way forward - Better world with Innovation for Sustainability?}

Is a better world possible with Innovation for Sustainability? This book presents a big picture view on IfS, notions of strategy and leadership, approaches to measurement and assessment, as well as views on tools methods and technologies to source the latest thinking and trends. Topics like the circular economy, digital platforms, experimentation and gamification emerged in this edited volume with international cross-disciplinary teams. As with any innovation, the outcome of such developments is hard to predict or control. For example, will car sharing business models actually reduce the number of cars on the road or sustain incumbents' car sales? (see e.g. Boons \& Bocken, 2018) Are energy efficient technologies (e.g. lights, appliances) leading to negative rebound effects such as using these more, because they are 'efficient' anyways? (Greening et al., 2000)

However, as suggested in our previously mentioned definition of IfS, the intentional design and assessment of impact are crucial. This means IfS is performed by entrepreneurial thinkers in all kinds of organisations (e.g. start-ups, SMEs, hybrid organisations, large business), but 
also by citizens using and co-creating newly designed products and services. Moreover, policy-makers are paving the way for different levels of innovation. The success of IfS thus depends on involvement at all actors at all levels, which has long been recognized in transitions studies (Geels, 2002; Markard et al., 2012). However, a proactive stance as well as involvement of actors at all levels becomes ever more pressing with increasingly pressing sustainability issues.

This book is also about change - exploring what is next. Our main goal as editors was to search for trailblazers and pioneering trends in research and practice. Indeed, many of the chapters introduce novel organizational practices and strategies, as well as improved ways to assess and measure impact of innovation in sustainability context. Furthermore, much of the research included in this book shows the need for IfS to integrate with trends such as digitalization, as well as experimentation and gamification.

This book has also shown ways to consolidation of organizational practices, and the implementation of sustainable business models. We are entering the third decade on the 21 st century. This will be an important period for business, sustainability and innovation. IfS displays multiple levels of action needed to interconnect individual sustainable leadership and entrepreneurship to the other levels of organizational transformation and systems transitions towards Sustainable Development. We see how business are becoming problem-solvers, aiming to provide solutions to grand challenges and fostering ways to adopt and build on Sustainable Development Goals. IfS is not a secondary goal anymore; it is a core approach for creating value at multiple levels: products, services, business models and system-level transitions. This reflects a necessary way forward for scholarly development. Beyond using sustainability as a context or target for innovation, we ask scholars to be even more ambitious in their attempts to theorize and conceptualize IfS, as well as developing interdisciplinary action research-based approaches. For instance, recent attempts draw from circular design principles and combine those with a business model approach from management studies to advance understanding of circular economy transitions (e.g. Bakker et al., 2014; Bocken et al., 2016; Den Hollander et al., 2017).

All in all, we have sought to contribute with a book that crosses topics, disciplines, as well as business and academia. We hope it will open up further debate and spur action to resolve our world's most pressing challenges through the lens of Innovation for Sustainability.

\section{References}

Adams, Richard, Sally Jeanrenaud, John Bessant, David Denyer, and Patrick Overy. "Sustainability-oriented innovation: a systematic review." International Journal of Management Reviews 18, no. 2 (2016): 180-205.

Bakker, Conny, Marcel den Hollander, Ed Van Hinte, and Yvo Zljlstra. Products that last: Product design for circular business models. TU Delft Library, 2014.

Battilana, Julie, and Silvia Dorado. "Building sustainable hybrid organizations: The case of commercial microfinance organizations." Academy of management Journal 53, no. 6 (2010): 1419-1440. 
Bocken, Nancy. M. P. "Sustainable venture capital-catalyst for sustainable start-up success?." Journal of Cleaner Production 108 (2015): 647-658.

Bocken, Nancy MP, Ingrid de Pauw, Conny Bakker, and Bram van der Grinten. "Product design and business model strategies for a circular economy." Journal of Industrial and Production Engineering 33, no. 5 (2016): 308-320.

Boons, Frank, and Nancy Bocken. "Towards a sharing economy-Innovating ecologies of business models." Technological Forecasting and Social Change (2018).

Boons, Frank, and Florian Lüdeke-Freund. "Business models for sustainable innovation: state-of-the-art and steps towards a research agenda." Journal of Cleaner production 45 (2013): 9-19.

Ceschin, Fabrizio, and Idil Gaziulusoy. "Evolution of design for sustainability: From product design to design for system innovations and transitions." Design Studies 47 (2016): 118-163.

den Hollander, Marcel C., Conny A. Bakker, and Erik Jan Hultink. "Product design in a circular economy: Development of a typology of key concepts and terms." Journal of Industrial Ecology 21, no. 3 (2017): 517-525.

Drucker, Peter Ferdinand. The practice of management: A study of the most important function in America society. Harper \& Brothers, 1954.

Ferraro, Fabrizio, Dror Etzion, and Joel Gehman. "Tackling grand challenges pragmatically: Robust action revisited." Organization Studies 36, no. 3 (2015): 363-390.

Geels, Frank W. "Technological transitions as evolutionary reconfiguration processes: a multi-level perspective and a case-study." Research policy 31, no. 8-9 (2002): 1257-1274.

George, Gerard, Jennifer Howard-Grenville, Aparna Joshi, and Laszlo Tihanyi.

"Understanding and tackling societal grand challenges through management research." Academy of Management Journal 59, no. 6 (2016): 1880.

Greening, Lorna A., David L. Greene, and Carmen Difiglio. "Energy efficiency and consumption — the rebound effect—a survey." Energy policy 28, no. 6-7 (2000): 389-401.

Hansen, Erik G., and Friedrich Grosse-Dunker. "Sustainability-Oriented Innovation Encyclopedia of Corporate Social Responsibility." (2012).

Hansen, Erik G., Friedrich Grosse-Dunker, and Ralf Reichwald. "Sustainability innovation cube - a framework to evaluate sustainability-oriented innovations." International Journal of Innovation Management 13, no. 04 (2009): 683-713.

Hart, Stuart L., and Mark B. Milstein. "Global sustainability and the creative destruction of industries." MIT Sloan Management Review 41, no. 1 (1999): 23.

Inigo, Edurne A., and Laura Albareda. "Understanding sustainable innovation as a complex adaptive system: a systemic approach to the firm". Journal of Cleaner Production, 126 (2016): 1-20. 
Inigo, Edurne A., Laura Albareda, L., and Paavo Ritala. "Business model innovation for sustainability: exploring evolutionary and radical approaches through dynamic capabilities". Industry and Innovation, 24, no. 5 (2017): 515-542.

Intergovernmental Panel on Climate Change (IPCC). "Global warming of $1.5^{\circ} \mathrm{C}$. Special Report" (2018).

Konietzko, Jan, Bocken, Nancy, and Hultink, Erik-Jan. "Business model experimentation for the circular economy in a service network context". 25TH IPDMC: Innovation and Product Development Management Conference, Porto, June 10-13 2018.

Kuratko, Donald F., Jeffery S. McMullen, Jeffrey S. Hornsby, and Chad Jackson. "Is your organization conducive to the continuous creation of social value? Toward a social corporate entrepreneurship scale." Business Horizons 60, no. 3 (2017): 271-283.

Markard, Jochen, Rob Raven, and Berhard Truffer, "Sustainability transitions: An emerging field of research and its prospects, Research Policy, vol 41 no. 6, (2012), 955-967.

Plieth, Hanna, Angelika C. Bullinger, and Erik G. Hansen. "Sustainable entrepreneurship in the apparel industry: The case of manomama." The Journal of Corporate Citizenship 45 (2012): 123.

Porter, Michael E., and Mark R. Kramer. "The big idea: Creating shared value." (2011).

Rockström, Johan, Will Steffen, Kevin Noone, Asa Persson, F. Stuart III Chapin, et al. "A safe operating space for humanity" Nature, 461 (2009): 472-5.

Steffen Will, Asa Persson, Lisa Deutsh, Jan Zalasiewics, Katherine Williams, Carole Crumley, Paul Crutzen, Carl Folke, Line Gordon, Mario Molina, Veerabhadran Ramanathan, Johan Rockström, Marten Scheffer, Joachim Schellnhuber, and Uno Svedin. The Anthropocene: From global change to Planetary Steardship. Ambio (2011) 40: 739-61.

Stubbs, Wendy, and Chris Cocklin. "Conceptualizing a "sustainability business model"." Organization \& Environment, vol. 21, no. 2 (2008): 103-127.

Tidd, Joe, John Bessant, and Keith Pavitt. Managing innovation integrating technological, market and organizational change. John Wiley and Sons Ltd, (2005). 